\title{
El género Sarocladium. W. Gams \& D. Hawksworth
}

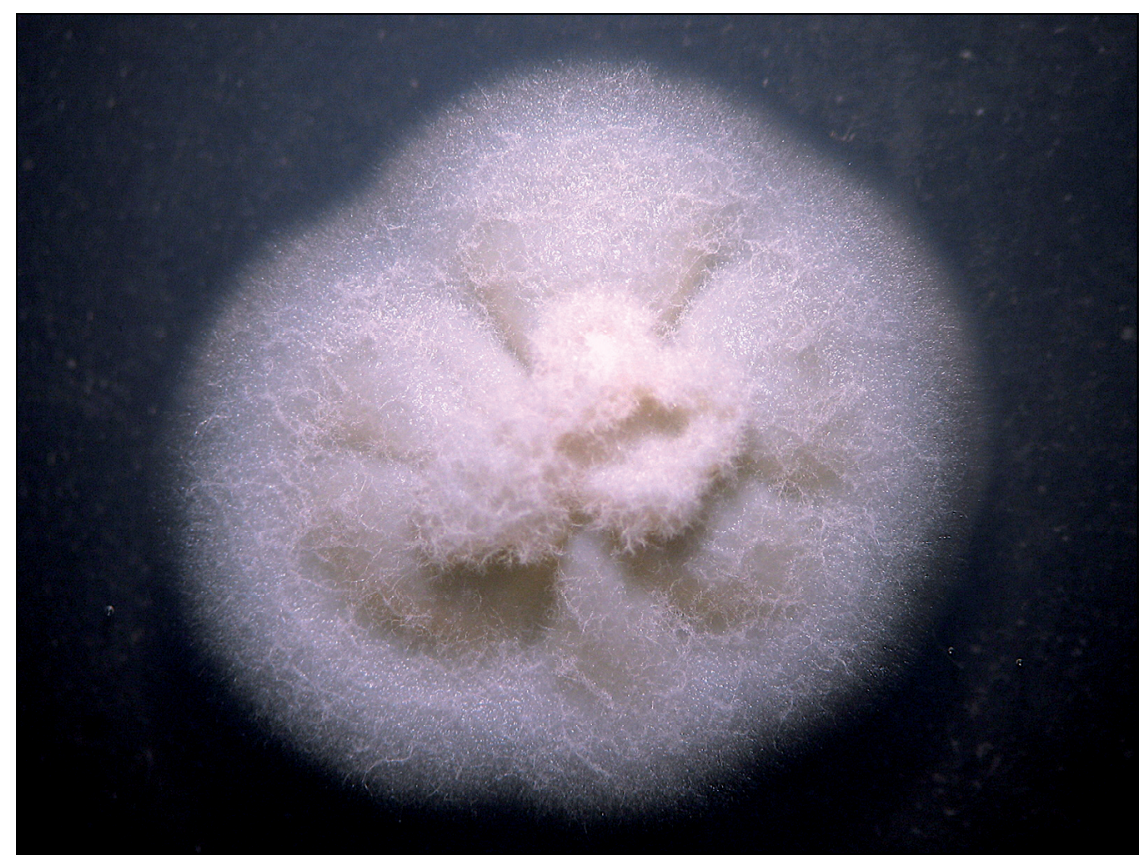

Figura 1. Colonia de Sarocladium kiliense en PDA obtenido de un hemocultivo de un paciente adulto neutropénico. Lupa estereoscópica. 4X.

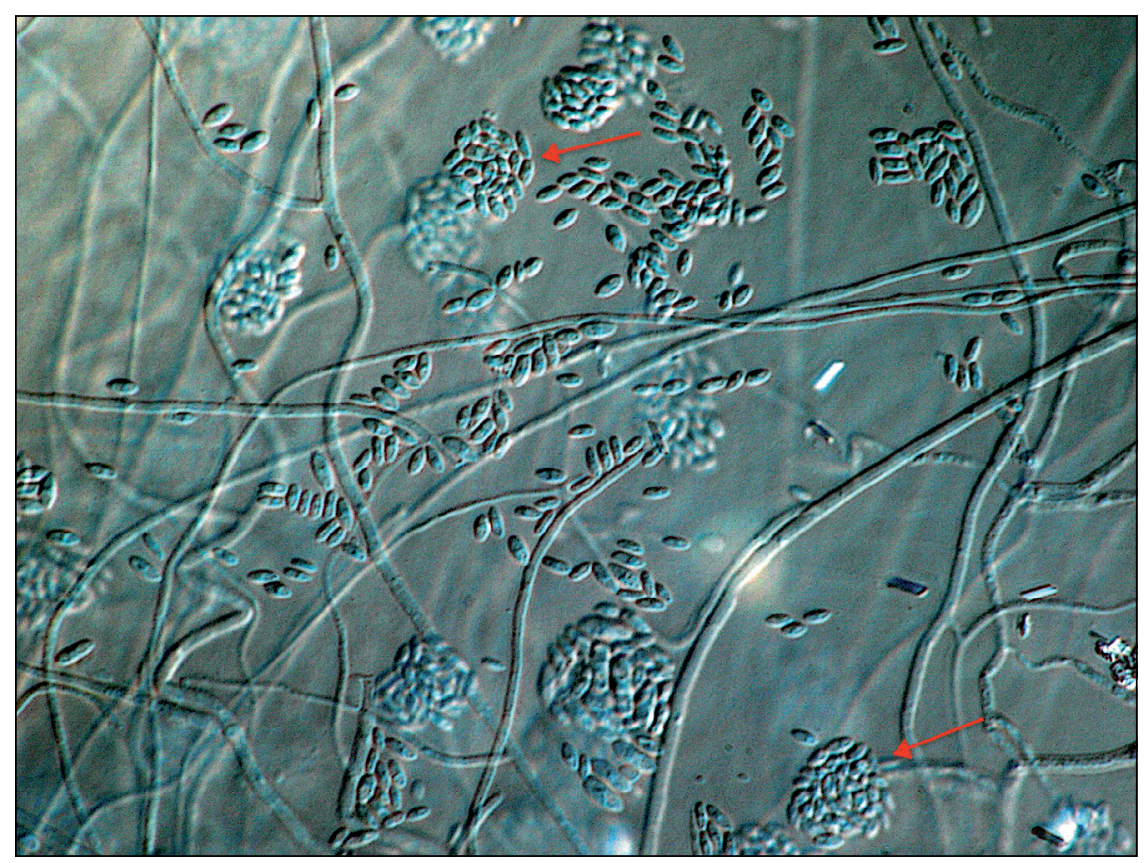

Figura 2. Conidios de Sarocladium kiliense dispuestos en falsas cabezas. Tinción de lactofenol con azul de algodón. 100X. 


\section{El género Sarocladium. W. Gams \& D. Hawksworth}

El género Sarocladium, inicialmente fue descrito con S. attenuatum y S. oryzae, dos patógenos del arroz que pueden provocar una reducción en la germinación, retardar el crecimiento del cultivo y pudrición de la vaina protectora de los granos. Basado en estudios filogenéticos, Summerbell et al., transfirieron varias especies del género Acremonium al género Sarocladium. Posteriormente, Giraldo et al., sobre la base de nuevos estudios filogenéticos describieron seis especies nuevas del género Sarocladium (S. bifurcatum, S. gamsii, S. hominis, S. pseudostrictum, S. subulatum y S. summerbellii).

Las especies clínicamente importantes son S. kiliense y S. strictum, sin embargo S. bifurcatum, S. hominis, S. pseudostrictum y $S$. subulatum, crecen a $35-37^{\circ} \mathrm{C}$, por lo que podrían provocar infecciones, aunque no se ha demostrado su rol en infecciones profundas.

Medios de cultivo: La caracterización morfológica de los aislamientos se debe realizar en cultivos de agar de avena y papa dextrosa (PDA).

Características macroscópicas: Colonias de crecimiento lento, de color crema a rosa (Figura 1). Algunas especies de $\mathrm{Sa}$ rocladium se caracterizan por la melanogénesis, produciendo un color gris-marrón oscuro al reverso del agar Sabouraud: S. glaucum, S. kiliense, y S. zeae. La melanogénesis es un factor de patogenicidad bien conocido en las enfermedades infecciosas.

Características microscópicas: Hifas estrechas y frágiles. Fiálides sobre todo en las hifas indiferenciadas, de paredes delgadas, cilíndricas y ligeramente ahusadas, se estrechan desde una anchura basal de 1,2-2,5 um; adelofialides frecuentemente presentes. Conidios elipsoidales a cilíndricos cortos, hialinos, acumulándose en falsas cabezas (Figura 2). Las clamidosporas pueden estar presentes.

Patogenicidad: Se han descrito distintas infecciones, desde queratitis y endoftalmitis, hasta peritonitis, endocarditis y fungemias. En Chile, durante el período de junio de 2013 a enero de 2014 hubo un brote de fungemias por S. kiliense en niños y adultos en quimioterapia, asociado a la administración de ondansetron endovenoso.

Tratamiento: La terapia óptima sigue siendo aún no bien conocida debido a la baja frecuencia de estas infecciones y la falta de datos clínicos, incluida la correcta identificación de las distintas especies en los aislamientos. Anfotericina B y voriconazol son las alternativas más aceptadas hasta el momento. Claramente la recuperación de la neutropenia es el mejor tratamiento y mejora el pronóstico.

\section{Referencias bibliográficas}

1.- Gams W, Hawksworth D L. The identity of Acrocylindrium oryzae Sawada and a similar fungus causing sheath-rot of rice. Kavaka 1975; 3: 57-61.

2.- Summerbell R C, Gueidan C, Schroers H J, de Hoog G S, Starink M, Rosete Y A, et al. Acremonium phylogenetic overview and revision of Gliomastix, Trichothecium and Sarocladium. Stud Mycol 2011; 68: 139-62.

3.- Giraldo A, Gené J, Sutton D A, Madrid H, de Hoog G S, Cano J, et al. Phylogeny of Sarocladium (Hypocreales). Persoonia 2015; 34: 10-24.

4.- Etienne K, Roe C, Smith R, Vallabhaneni S, Duarte C, Escandón P, et al. Whole-Genome Sequencing to Determine Origin of Multinational Outbreak of Sarocladium kiliense Bloodstream Infections. Emerg Infect Dis 2016; 22 (3): 476-81.

5.- Tortorano A M, Richardson M, Roilides E, van Diepeningen A, Caira M, Muñoz P, et al. ESCMID and ECMM joint guidelines on diagnosis and management of hyalohyphomycosis: Fusarium spp., Scedosporium spp. and others. Clin Microbiol Infect 2014; 20 (3): 27-46.

Rodrigo Cruz, Peggy Vieille y Laura Carvajal Laboratorio de Micología. Universidad de Valparaíso.

Correspondencia a: Rodrigo Cruz rodrigo.cruz@uv.cl 